\title{
Cerebellar Low-Grade Oligoastrocytoma Presenting with Subarachnoid Haemorrhage
}

\author{
Subaraknoid Kanama ile Başvuran Serebellar Düşük Dereceli \\ Oligoastrositom
}

Gopalakrishnan VISWANATHAN ${ }^{1}$, Suresh NAIR ${ }^{1}$, Kesavadas CHANDRASEKHAR ${ }^{2}$, Radhakrishnan VISHNUPURI ${ }^{3}$

${ }_{1}^{1}$ Sree Chitra Tirunal Institute for Medical Sciences and Technology, Department of Neurosurgery, Trivandrum, Kerala, India

${ }^{2}$ Sree Chitra Tirunal Institute for Medical Sciences and Technology, Department of Radiology, Trivandrum, Kerala, India

${ }^{3}$ Sree Chitra Tirunal Institute for Medical Sciences and Technology, Department of Pathology, Trivandrum, Kerala, India

Correspondence address: Gopalakrishnan VISWANATHAN / E-mail: doc_gopal@yahoo.com

\begin{abstract}
Subarachnoid haemorrhage (SAH) associated with intra-axial tumours is extremely uncommon and is usually seen in association with intratumoural bleed. Tumours located near the ventricle or subarachnoid spaces have a higher propensity for SAH compared to intraparenchymal lesions. Low-grade tumours rarely demonstrate any evidence of bleed on imaging. Oligoastrocytomas of the posterior fossa are rare tumours in adults and their presentation with intratumoural haemorrhage and SAH is unknown. We report a unique case of cerebellar low-grade oligoastrocytoma that mimicked a tentorial-based extraaxial lesion on imaging and presented with SAH. Susceptibility-weighted magnetic resonance imaging is a useful imaging modality to demonstrate blood within and outside the tumour.
\end{abstract}

KEYWORDS: Oligoastrocytoma, Subarachnoid haemorrhage, Susceptibility-weighted imaging, Intratumoural bleed

öz

Intraaksiyal tümörlerle ilişkili subaraknoid kanama (SAK) çok nadirdir ve genellikle bir intratümöral kanamayla ilişkili olarak görülür. Ventrikül veya subaraknoid boşluklara yakın bulunan tümörlerin intraparenkimal lezyonlara göre daha yüksek SAK oluşturma eğilimi vardır. Düşük sınıfı tümörler görüntülemede çok nadiren herhangi bir kanama bulgusu gösterirler. Posterior fossa oligoastrositomları yetişkinlerde nadir tümörlerdir ve intratümöral kanama ve SAK ile ortaya çıkabildikleri bilinmektedir. Görüntülemede tentoriyal bazlı ekstra aksiyal bir lezyonu andıran ve SAK ile gelen nadir bir serebellar düşük sınıflı origoastrositom vakası sunuyoruz. Duyarlılık ağırlıklı manyetik rezonans görüntüleme tümör içinde ve dışında kanı göstermek için faydalı bir görüntüleme modalitesidir.

ANAHTAR SÖZCÜKLER: Oligoastrositom, Subaraknoid kanama, Duyarlılık ağırlıklı görüntüleme, İntratümoral kanama

\section{INTRODUCTION}

Brain tumors are a known cause of spontaneous (nontraumatic) intracranial haemorrhage with a symptomatic tumor-bleeding rate of about $10 \%$ or less. Subarachnoid haemorrhage (SAH) associated with brain tumors usually develop secondary to intratumoural bleed (10). Mixed gliomas are predominantly supratentorial tumours and their location in the cerebellum in adults is uncommon. These lesions are known to show evidence of intratumoural bleed presumably because of the oligodendroglial component. Oligoastrocytomas presenting clinically and radiologically with SAH have not been reported till date. We report a case of cerebellar low-grade (Grade II) oligoastrocytoma, containing both fibrillary astrocytes and oligodendroglioma that mimicked an extraaxial infratentorial lesion on imaging and presented with $\mathrm{SAH}$. The diagnosis of SAH was evident on susceptibility-weighted magnetic resonance imaging even prior to surgery.

\section{CASE REPORT}

A 30-year-old man presented with a two-week history of acute onset, severe occipital headache not associated with vomiting or any visual symptoms. The pain subsided with analgesics but he continued to have mild headache and neck pain for which he did not seek any medical attention. Five days prior to admission he noticed gait unsteadiness with a tendency to fall to his right side. The patient had no remarkable medical history and had not suffered from any recent head trauma. On clinical examination, he was alert and fundoscopy revealed papilloedema. Right-sided cerebellar signs were positive. A routine haematological workup and coagulation profile was within normal limits.

\section{Radiology}

Computed tomographic (CT) scanning of the brain revealed a predominantly cystic mass lesion with peripheral rim calcification (Figure 1A) and contrast enhancement in 


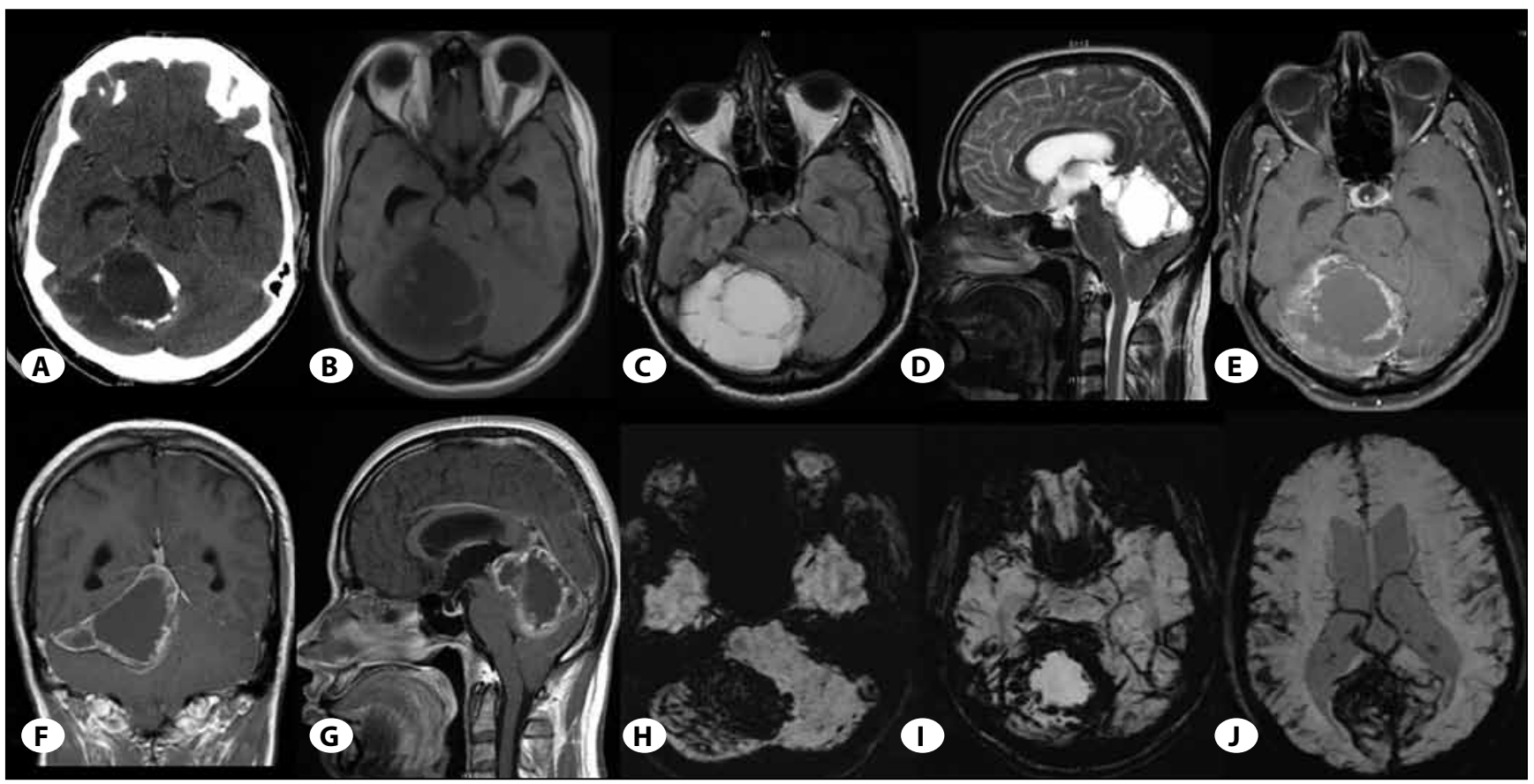

Figure 1: Axial CT brain (A) reveals a cystic mass lesion in the right cerebellar hemisphere with peripheral rim calcification. Axial T1weighted, axial FLAIR and sagittal T2-weighted MR images (B, C, D) shows the cystic tumor to be multiloculated with solid areas and a broad base towards the tentorium. Note the tonsillar herniation. Contrast enhanced coronal, axial and sagittal T1-weighted images $(\mathbf{E}, \mathbf{F}, \mathbf{G})$ shows enhancement of the margins of the lesion, the septations and the tentorium. Susceptibility-weighted MRI (H, I, J) shows areas of blooming within the tumor suggestive of bleed. The blooming within the sulci is due to SAH.

the right cerebellar hemisphere. Magnetic Resonance Imaging (MRI) showed a large well-defined multiloculated cystic lesion with solid areas and a broad base towards the tentorium. The margins of the tumour, the septations within the cysts and the tentorium were noted to enhance after gadolinium administration. A small solid enhancing area was also noted within the tumour. There was herniation of the cerebellar tonsil with pressure effect on the fourth ventricle and resultant obstructive hydrocephalus (Figure 1B-G). The possibility of an extra-axial cystic tumour such as a cystic meningioma was considered. The susceptibility-weighted MRI (Figure $1 \mathrm{H}-J$ ) showed areas of blooming not only restricted to the areas of calcification but also within the cystic areas. There was blooming surrounding the margins of the lesion. These areas could represent the presence of blood products within the mass and surrounding the mass. Few of these linear hypointensities could be due to veins with increased deoxyhaemoglobin. The supratentorial compartment showed hypointensities within the sulci. These could represent blood products within the subarachnoid space and were thought to be suggestive of SAH. The evidence of bleed within the mass raised the possibility of a cystic schwannoma. The possibility of glioma was considered to be low in the diagnosis since the mass was apparently in an extra-axial location.

\section{Surgery}

The patient underwent a right retromastoid suboccipital craniectomy in the park bench position. On opening the dura, the tumour was intra-axial in location, inseparable and indistinguishable from the normal cerebellar parenchyma. It was vascular, brownish-yellow with solid and cystic areas. The cystic component contained dark brown fluid with clots and the surrounding parenchyma was hemosiderin stained. The medial wall of the tumour showed calcification and had a gritty consistency. The lesion was adherent to the inferior surface of the tentorium from which it was gradually dissected. We could achieve only a near total excision due to the poor plane of separation at its medial aspect.

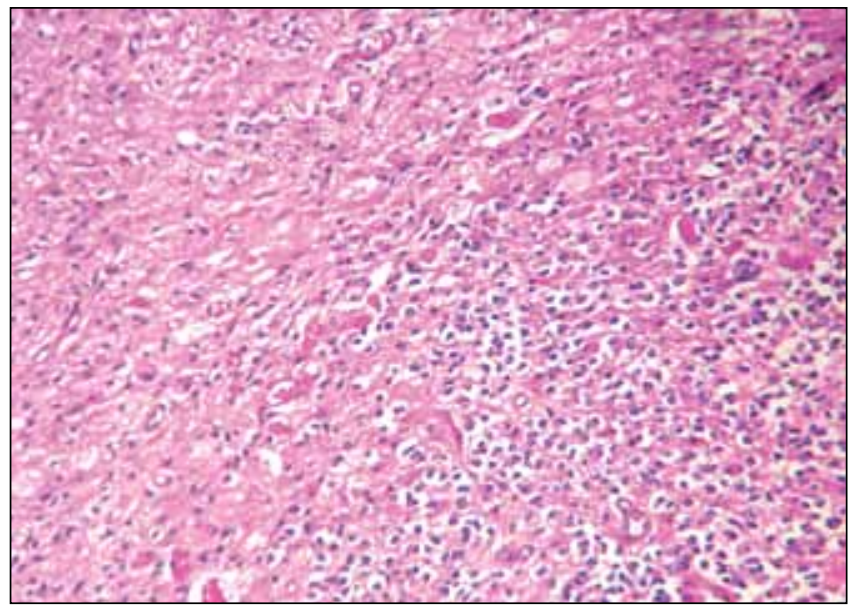

Figure 2: Photomicrograph showing features of a low-grade oligoastrocytoma. The neoplastic cells are composed by an admixture of oligodendroglial cells and fibrillary astrocytes supported on a glial fibrillary matrix (H \& E, X200). 


\section{Postoperative course}

The patient had an uneventful recovery. CT imaging showed a small residual lesion at the medial wall of the tumor. The patient was discharged five days after surgery. In view of a residual lesion, the patient was referred for external beam radiotherapy. After radiotherapy, the patient is on regular follow up and is asymptomatic. One year after radiotherapy, imaging revealed the residual lesion to be static in size.

\section{Histopathology}

Five-micron thin paraffin section of the surgical specimen showed features of a neoplastic lesion of glial origin (Figure 2). The neoplastic glial cells were composed of an admixture of diffusely arranged stellate shaped fibrillary astrocytes as well as monomorphic looking oligodendroglial cells. Both the components appeared to be of even distribution in all the foci examined. The oligidendroglial component was positive for $1 \mathrm{p} 19 \mathrm{q}$ deletion. Discrete as well as confluent aggregates of calcification were seen essentially confined to the oligodendroglial component. Foci of haemorrhages were also seen in the neoplasm. Proliferation rates (based on MIB1 immunoassaying) were 2-3\%. A pathologic diagnosis of Grade II oligoastrocytoma was therefore made.

\section{DISCUSSION}

The incidence of tumour bleeding varies among published reports, ranging from 1.3 to $9.6 \%(1,9)$. This is higher in children maybe due to the larger size of the tumour or to the higher frequency of malignant tumours. Metastatic brain tumours, glioblastomas, medulloblastomas, primitive neuroectodermal tumors and pituitary tumours often present with intratumoural haemorrhage (2). SAH associated with an intra-axial tumor has seldom been reported, comprising an incidence of $1.3 \%$ in one report (3) and is usually secondary to intratumoural bleed (10). Intracranial tumor related bleeding might result from disruption of tumour related vessels by the expanding lesion, direct infiltration of vessels, structural abnormalities of tumour vessels or endothelial proliferation causing vessel occlusion, tumour necrosis and haemorrhage. Tumours that are located near the ventricle or the subarachnoid space are more likely to cause SAH than intracerebral haematoma when they bleed.

Our case is unique because of several reasons. Firstly, oligoastrocytomas are largely supratentorial tumours of adulthood that favour the frontal and temporal lobes. Their occurrence in the posterior fossa is very rare except in childhood. Secondly, to the best of our knowledge, low-grade oligoastrocytoma presenting with SAH is not reported in the literature. In a study by Wakais et al. (9) only one case of mixed glioma out of a total of 1861 brain tumours studied showed evidence of haemorrhage though the article does not cite the nature of the bleed. Specht et al. (8) reported an 8 year-old child with massive cerebellar haemorrhage where autopsy revealed haematoma within a mixed glioma containing both juvenile pilocytic astrocytoma and oligodendroglioma. Oligodendrogliomas have a propensity to bleed within themselves as they contain thin-walled vessels that may be susceptible to rupture. This could be the reason for intratumoural haemorrhage in our case though there was no evidence of abnormal endothelial proliferation as evidenced by Specht et al (8). Diffuse SAH may possibly represent the "exteriorized" component of intratumoural bleeds that are classic but rare events in the natural history of gliomas. The extent of SAH is probably decided by the acuteness of the event and the intratumoral pressure generated. Lastly, this tumour on imaging masqueraded an extraaxial lesion. The possibility of an atypical cystic meningioma or a cystic schwannoma was considered. Both these tumours are uncommonly known to present with SAH (6). During surgery, the tumour was adherent to the tentorium and had multiple dural feeders secondarily supplying the tumour. Only tissue pathology could conclusively give the diagnosis. This highlights the rare pitfalls in neuroimaging that can still occur despite rapid technical advancements.

Susceptibility-weighted imaging (SWI) is an MRI technique that is exquisitely sensitive to paramagnetic substances, such as deoxygenated blood, blood products, iron, and calcium $(4,7)$. Old blood products such as hemosiderin due to previous SAH are picked up by this sequence. Susceptibility-weighted imaging (SWI) allows detection of haemorrhage as early as $6 \mathrm{~h}$ and can reliably detect acute intracerebral parenchymal, as well as subarachnoid haemorrhage. It detects early haemorrhagic transformation within an infarct and provides insight into the cerebral haemodynamics following stroke. It helps in the diagnosis of cerebral venous thrombosis. It also has applications in the work-up of stroke patients. The sequence helps in detecting microbleeds in various conditions, such as vasculitis, cerebral autosomal dominant arteriopathy, subacute infarcts and leucoencephalopathy (CADASIL), amyloid angiopathy, and Binswanger's disease. The sequence also aids in the diagnosis of vascular malformations and perinatal cerebrovascular injuries. The blooming within the tumor as was noted in our patient represented areas of bleed within it. In all probability the tumor capsule would have ruptured into the subarachnoid space and produced $\mathrm{SAH}$. The low signal seen in SWI within and surrounding the tumor could have also been due to calcification/ microcalcifications or increased deoxyhaemoglobin (5). However the hypointensities seen were larger and extended much beyond the areas of calcification visualized in $\mathrm{CT}$. The extension of hypointensities to supratentorial subarachnoid spaces raised the suspicion of SAH. It is unlikely that the low signal is due to a leptomeningeal spread of the hemorrhagic oligoastroglial tumor because no abnormal enhancement was noted in the leptomeningeal space.

In conclusion, we describe a unique case of a grade II oligoastrocytoma located in the posterior fossa of an adult patient presenting with intratumoural bleed and $\mathrm{SAH}$. This is of clinical importance, as mixed gliomas should be considered in the differential diagnosis of low-grade tumours that can present with haemorrhage. MRI may at times fail to clearly differentiate extraaxial from an intraaxial tumor and one is in for a diagnostic surprise after surgery and histopathology. 
Our report highlights the necessity of susceptibility-weighted MRI sequences in neuro-oncology for identifying tumor related bleed preoperatively. This is necessary especially for early identification of SAH related complications.

\section{REFERENCES}

1. Bitoh S, Hasegawa H, Ohtsuki H, Obashi J, Fujiwara M, Sakurai M: Cerebral neoplasms initially presenting with massive intracerebral hemorrhage. Surg Neurol 22(1): 57-62, 1984

2. Lee CS, Huh JS, Sim KB, Kim YW: Cerebellar pilocytic astrocytoma presenting with intratumor bleeding, subarachnoid hemorrhage, and subdural hematoma. Childs Nerv Syst 25(1): 125-128, 2009

3. Locksley HB, Sahs AL, Sandler R: Report on the cooperative study of intracranial aneurysms and subarachnoid hemorrhage. 3. Subarachnoid hemorrhage unrelated to intracranial aneurysm and A-V malformation. A study of associated diseases and prognosis. J Neurosurg 24(6): 1034-56, 1966

4. Mittal S, Wu Z, Neelavalli J, Haacke EM: Susceptibility-weighted imaging: Technical aspects and clinical applications, part 2. AJNR Am J Neuroradiol 30(2): 232-252, 2009
5. Reichenbach JR, Barth M, Haacke EM, Klarhöfer M, Kaiser WA, Moser E: High-resolution MR venography at 3.0 Tesla. J Comput Assist Tomogr 24(6): 949-957, 2000

6. Rim NJ, Kim HS, Kim SY: A "benign" sphenoid ridge meningioma manifesting as a subarachnoid hemorrhage associated with tumor invasion into the middle cerebral artery. Korean J Radiol 9 Suppl:10-13, 2008

7. Santhosh K, Kesavadas C, Thomas B, Gupta AK, Thamburaj K, Kapilamoorthy TR: Susceptibility weighted imaging: A new tool for magnetic resonance imaging of stroke. Clin Radiol 64:74-83, 2009

8. Specht CS, Pinto-Lord C, Smith TW, DeGirolami U, Suran E, Marshall PC, Davidson RI: Spontaneous hemorrhage in a mixed glioma of the cerebellum: Case report. Neurosurgery 19(2): 278-281, 1986

9. Wakai S, Yamakawa K, Manaka S, Takakura K: Spontaneous intracranial hemorrhage caused by brain tumor: Its incidence and clinical significance. Neurosurgery 10(4): 437-444, 1982

10. Yokota A, Kajiwara H, Matsuoka S, Kohchi M, Matsukado Y: Subarachnoid hemorrhage from brain tumors in childhood. Childs Nerv Syst 3(2): 65-69, 1987 